\title{
Economically viable isolation and characterization of oleanolic acid from Eugenia caryophyllus (Spreng.)
}

\author{
Nilesh B. Banarase ${ }^{1,2 *}$, Chanchal D. Kaur ${ }^{1}$ \\ ${ }^{1}$ Dept. of Pharmaceutical Sciences, Shri Rawatpura Sarkar Institute of Pharmacy, Kumhari, Durg, India \\ ${ }^{2}$ Dept. of Pharmacognosy \& Phytochemistry, Apollo College of Pharmacy, Anjora, Durg, India \\ *Corresponding author: nbanarase7@gmail.com
}

\begin{abstract}
Oleanolic acid is an interesting molecule found widespread throughout the plant kingdom with promising pharmacological activities. However, the utilization of oleanolic acid in the modern therapy is quite difficult due to the lack of proper isolation method and selection of commercially available raw materials. In the present study, the new economically viable method for the isolation of oleanolic acid from flower buds of Eugenia caryophyllus (Spreng.), commonly known as clove bud, was developed. The yield of oleanolic acid was found to be $1.8 \mathrm{~g} / 100 \mathrm{~g}$ dry matter (1.8\%). The isolated oleanolic acid was characterized by DSC, TLC, FTIR, ESI-HRMS, and NMR studies. The purity of isolated oleanolic acid was determined by HPLC studies, and it was found to be $97.7 \%$ pure. The method so developed is simple and cost-effective with industrial applicability.
\end{abstract}

Keywords: Characterization; Eugenia caryophyllus (Spreng.); isolation; oleanolic acid; purity.

\section{Introduction}

Oleanolic acid (3ß-hydroxy-olea-12-en-28-oic acid) (Figure 1) is a fantastic pentacyclic triterpenoid molecule found widespread throughout the plant kingdom in more than 1600 plant species (Fai, 2009; Lu et al., 2013).

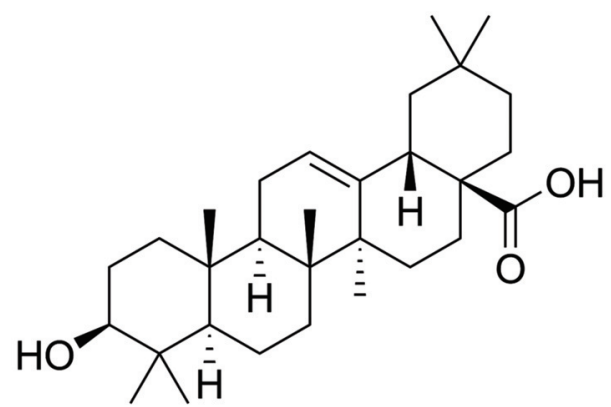

Fig. 1. Structure of oleanolic acid (3ß-hydroxy-olea-12en-28-oic acid).

It is generally associated with the protection from pathogen and water loss in the plants (Heinzen et al., 1996). Besides that, oleanolic acid and its derivatives possess various pharmacological activities such as hepatoprotective, anti-inflammatory, anti-cancer, and antiHIV that are paid special attention in the present situation for the treatment and management of various diseases
(Liu, 1995; Sultana \& Ata, 2008; Paszel-Jaworska et al., 2014; Shanmugam et al., 2014; Xu et al., 2014; Isah et al., 2016; Ayeleso et al., 2017; Kim et al., 2018; Liu et al., 2019; Duan et al., 2019).

Although oleanolic acid is found widely among the plant kingdom, the main hurdles to utilize the said molecule commercially are its low content in the crude drug, shortage of crude drugs as a raw material, and the lack of economically viable method for its isolation.

Most of the oleanolic acid containing crude drugs are not cultivated commercially, which deprives the availability of raw materials, and the previously reported isolation methods are not inventive (Table 1) to meet the industrial needs.

This prompted us to search for a crude drug with ease availability and richness in oleanolic acid content, and that is when Eugenia caryophyllus (syn- Syzygium aromaticum) flower buds caught our attention. Eugenia caryophyllus, commonly known as clove bud, has been utilizing for a century as a common spice and has various medicinal uses. 
Clove is a tropical plant that grows up to a height of $15 \mathrm{~m}$ at warm humid climate. Seeds are generally sown from August to October, and it is necessary to sow them immediately after collection as they lose viability within one week after harvesting. The clove tree begins to yield the cloves from the seventh to the eighth year, and full bearing stage attains after about (15-20) years. It attains the flowering season from September to October and is ready for harvesting in about four months. It is collected by hand or beating with bamboos before the white corolla opens.

It is unopened dried flower bud with crimson to dark brown in color with aromatic odor and taste producing numbness of tongue. It is about (10-17) $\mathrm{mm}$ in length, 4 $\mathrm{mm}$ in width, and $2 \mathrm{~mm}$ thick. Hypanthium is surmounted with four thick divergent sepals surrounded by dome shaped corolla. The corolla consists of unexpanded membranous petals with several stamens and single stiff prominent style (Rangari, 2012).

The large utilization of cloves worldwide made their commercial development in the Asian countries. Nowadays, various countries like India, Indonesia, Sri Lanka, Tanzania, and Madagascar are commercially producing the cloves (Kamatou et al., 2012). Moreover, the oleanolic acid content of the clove is relatively high (2\%) (Nowak et al., 2013).

These literature studies have encouraged us to develop an economically viable method for the isolation of pure oleanolic acid from the flower buds of E. caryophyllus with higher yield.

\section{Materials and methods}

\subsection{Chemicals and reagents}

Pure oleanolic acid was purchased from Yucca Enterprises, Mumbai, India. All the solvents for extraction and isolation were of analytical grade. The HPLC grade solvents for HPLC study were purchased from Merck Chemicals, Mumbai, India, while, for the NMR analysis, the deuterated solvents were used.

\subsection{Procurement and authentication of plant material}

As cloves are commercially available in the market, good quality cloves (ATC ${ }^{\circledR}$ Spices) were purchased from the Durg city of Chhattisgarh state, India. The said plant specimen has been authenticated as Eugenia caryophyllus (Spreng.) Bullock \& S.G. Harrison belonging to the family Myrtaceae from the Botanical Survey of India, Central National Herbarium, Howrah-711 103, India (No. SRSIP- BC7582/01).

\subsection{Extraction and isolation}

a) $100 \mathrm{~g}$ E. caryophyllus flower buds (cloves) were firstly washed twice with distilled water (to remove any adhered undesired foreign substances) and dried in the oven at 35 $40{ }^{\circ} \mathrm{C}$.

b) Dried cloves were further boiled with distilled water in a beaker for (40-45) minutes (it was a necessary step as we were using ethyl alcohol as a solvent for the extraction. It helped remove any polar substances within cloves but not oleanolic acid, which is hydrophobic in nature) and filtered. We rinsed the cloves twice with distilled water and discarded the water extract.

c) We dried the cloves in a hot air oven at $35-40{ }^{\circ} \mathrm{C}$. We then transferred the cloves in the $500 \mathrm{ml}$ round bottom flask and reflux with $150 \mathrm{ml}$ ethyl alcohol at $80{ }^{\circ} \mathrm{C}$ on a heating mantle for 90 minutes (there was no need to powder the cloves because we found no change in the yield of oleanolic acid, and also the powdered material could produce the problems of clogging during filtration).

d) Now, filter the hot content (to avoid early crystallization). Transfer the ethanolic extract in another $250 \mathrm{ml}$ round bottom flask and decolorize it with activated charcoal for about 30 minutes using reflux assembly (charcoal helped remove the unwanted pigment from the ethanolic extract).

e) Filter the hot content. Concentrate the ethanolic extract up to $50 \mathrm{ml}$ and allow it to cool at room temperature. About $100 \mathrm{ml}$ of distilled water was added slowly with constant stirring and was kept in the refrigerator to precipitate the crude oleanolic acid.

f) Filter the crude oleanolic acid, wash it thrice with distilled water, and dry it in a hot air oven at $40{ }^{\circ} \mathrm{C}$. Further, crystallize the oleanolic acid by methanol. The experiment was repeated three times to ensure the reproducibility of the proposed method. 







\subsection{Melting point determination}

The melting point was determined by using laboratory melting point apparatus (Adarsh Scientific ${ }^{\circledR}$, India). A sample of an isolated oleanolic acid was inserted in the capillary tube and put into a slot behind the viewfinder of apparatus along with the thermometer at a neighboring slot. Turn on the apparatus and heat it at a medium rate, and the melting temperature range was noted down.

Further, as per the literature (Widmann and Scherrer, 1991; Araújo et al., 2010), the melting point can be determined satisfactorily using Differential Scanning Calorimetry (DSC). DSC thermograph of an isolated oleanolic acid was conducted using DSC 6000 (Perkin Elmer, USA). The DSC cell was purged using nitrogen gas at $20 \mathrm{ml} / \mathrm{min}$. A heating rate of $5{ }^{\circ} \mathrm{C} / \mathrm{min}$ was used to scan from 30 to $360{ }^{\circ} \mathrm{C}$. The result was analyzed using Pyris 6 DSC software version 11.0.0.0449.

\subsection{Thin layer chromatography (TLC)}

Thin layer chromatography (TLC) was performed using analytical precoated TLC plates (Merck, $1 \mathrm{~mm}$ thick, silica gel $\left.60 \mathrm{~F}_{254}\right)$. The plate was prewashed with methanol and dried before use.

A small quantity of standard oleanolic acid, isolated oleanolic acid, and ethanolic extract of cloves was dissolved in $5 \mathrm{ml}$ methanol and applied on the plate. The plate was developed in a mobile phase, petroleum ether:ethyl acetate (8.2:1.8). After complete development, the plate was dried for 10 minutes and sprayed with $10 \%$ (v/v) ethanol solution of sulfuric acid and then heated to $120{ }^{\circ} \mathrm{C}$ for 3 minutes in a hot air oven. The visualized spots were documented in daylight and in UV at $366 \mathrm{~nm}$.

\subsection{Fourier transform infrared spectroscopy (FTIR)}

Fourier transform infrared (FTIR) spectrums of an isolated oleanolic acid were recorded on sample prepared in $\mathrm{KBr}$ disk using FTIR spectrophotometer model RZX (Perkin Elmer, USA). The scanning range was $400-4000 \mathrm{~cm}^{-1}$.

\subsection{High resolution electrospray ionization mass spectrometry (ESI-HRMS)}

The isolated oleanolic acid was analyzed by using high resolution electrospray ionization mass spectrometry (ESI-HRMS). The high resolution spectrum was recorded on mass spectrometer, Model- Impact $\mathrm{HD}^{\mathrm{TM}}$ (Bruker Daltonik GmbH, Germany). Nitrogen was used as a drying gas at $200{ }^{\circ} \mathrm{C}$. The sample solution was introduced continuously via a syringe pump with a flow rate of 0.120 $\mathrm{ml} /$ min with a charging voltage of $2000 \mathrm{~V}$ and evaluated by Bruker Compass Data Analysis 4.2 software.

\subsection{Nuclear magnetic resonance (NMR)}

${ }^{13} \mathrm{C}$ and ${ }^{1} \mathrm{H}$ NMR spectra were recorded on NMR spectrometer Model ECZR series $600 \mathrm{MHz}$ (JEOL, Japan) in solvent $\mathrm{CDCl}_{3}$. Chemical shifts $(\delta)$ were given in ppm. The spectra were evaluated by Delta NMR Data Processing Software.

2.9 High performance liquid chromatography (HPLC)

HPLC- 20A system (Shimadzu, Japan) with LC-20 AT pump, SPD-M20A Photo Diode Array (PDA) detector, and Betasil C18 column (Dim-150mm $\times 4.6 \mathrm{~mm}$, particle size-5 $\mu \mathrm{m}$ ) was used. The elution of oleanolic acid was carried out at $0.6 \mathrm{ml} / \mathrm{min}$ flow rate using a mobile phase composed of 1\% orthophosphoric acid:methanol (10:90). The column temperature was set at $27{ }^{\circ} \mathrm{C}$. The injection volume was $20 \mu \mathrm{L}$. The samples were detected and quantified at $210 \mathrm{~nm}$.

To study the linearity of standard oleanolic acid, the serial dilutions of standard stock solution were prepared in methanol in the range of $5-80 \mu \mathrm{g} / \mathrm{ml}$ and filtered using $0.22 \mu \mathrm{m}$ Nylon 66 syringe filter. A calibration curve was plotted as concentration of oleanolic acid versus absorption peak area.

A sample solution of an isolated oleanolic acid $(60 \mu \mathrm{g} /$ $\mathrm{ml}$ ) was used to determine the purity of compound.

The purity of an isolated oleanolic acid was calculated using following equation:

$\mathrm{P}=(\mathrm{F} / \mathrm{T}) \times 100 \%$

where

$\mathrm{P}$ - Purity of an isolated oleanolic acid (\%)

F - Amount of analyte (oleanolic acid) found

$\mathrm{T}$ - Amount of analyte (oleanolic acid) taken.

\section{Result and discussion}

Regarding the investigation of the proposed method, oleanolic acid was isolated, and it appeared as a light yellow amorphous powder on crystallization with a yield of $1.8 \mathrm{~g} / 100 \mathrm{~g}$ dry matter $(1.8 \%)$.

The melting point of the isolated oleanolic acid on the laboratory melting point apparatus was found to be 306-308 ${ }^{\circ} \mathrm{C}$. In case of DSC analysis (Figure 2), the 
endothermic peak at $306.538{ }^{\circ} \mathrm{C}$ denoting the melting point of an isolated oleanolic acid corresponds well with that given in the literature (Reyes-Zurita et al., 2016).

As per the TLC study (Figure 3), it was found that the oleanolic acid (standard, isolated, and in ethanolic extract of E. caryophyllus) was visualized as a pink spot under 366 $\mathrm{nm}$ in $\mathrm{UV}$ and daylight corresponding to the $\mathrm{R}_{\mathrm{f}}$ value 0.23 .
The isolated oleanolic acid showed the characteristics absorption band for-OH $\left(3431.2 \mathrm{~cm}^{-1}\right)$, -OH of carboxylic group $\left(2924.2 \mathrm{~cm}^{-1}\right), \mathrm{C}=\mathrm{C}\left(1692.7 \mathrm{~cm}^{-1}\right)$, and $-\mathrm{CH}_{3}(1463.4$ $\mathrm{cm}^{-1}$ ) supported well previous reports (Li et al., 2013).

ESI-HRMS analysis of an isolated oleanolic acid showed the adduct peak.

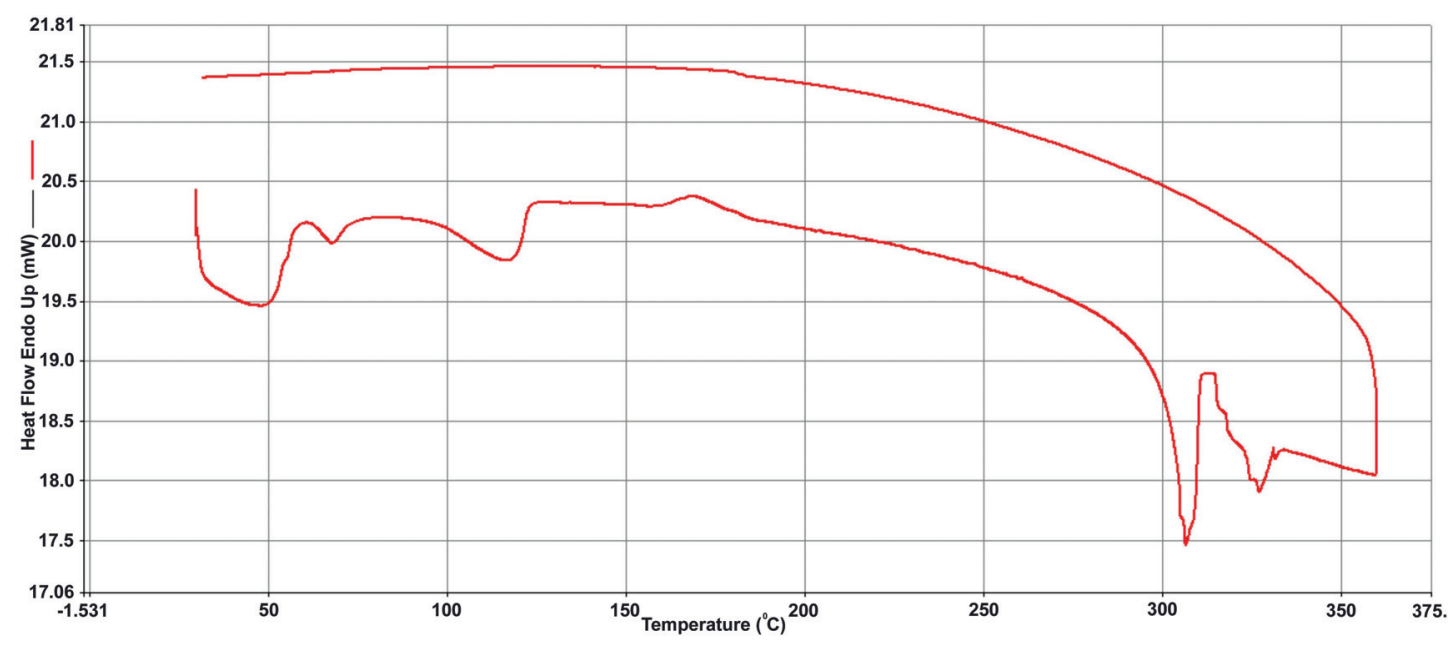

Fig. 2. DSC thermogram of an isolated oleanolic acid.

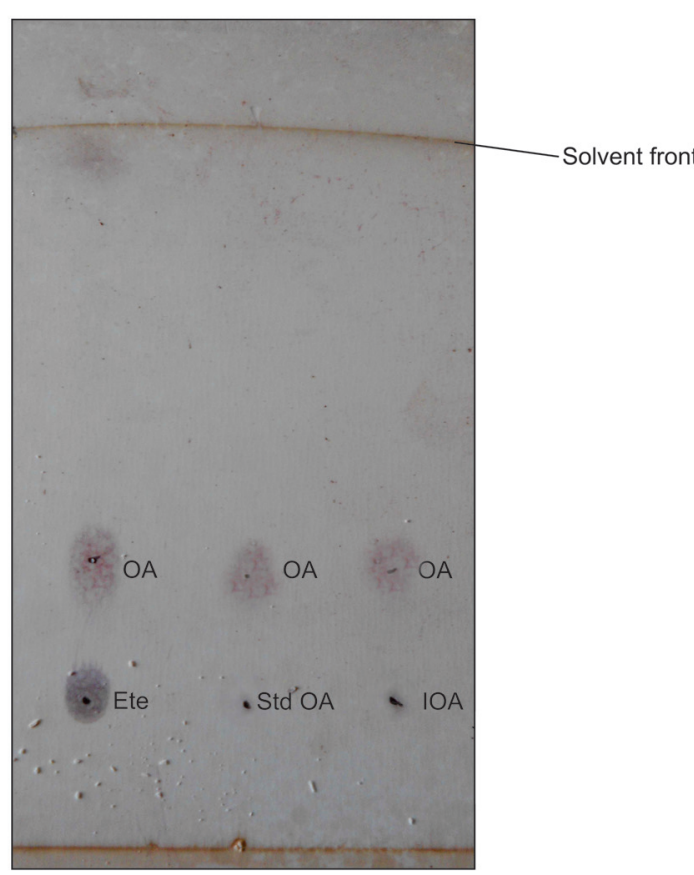

(A)

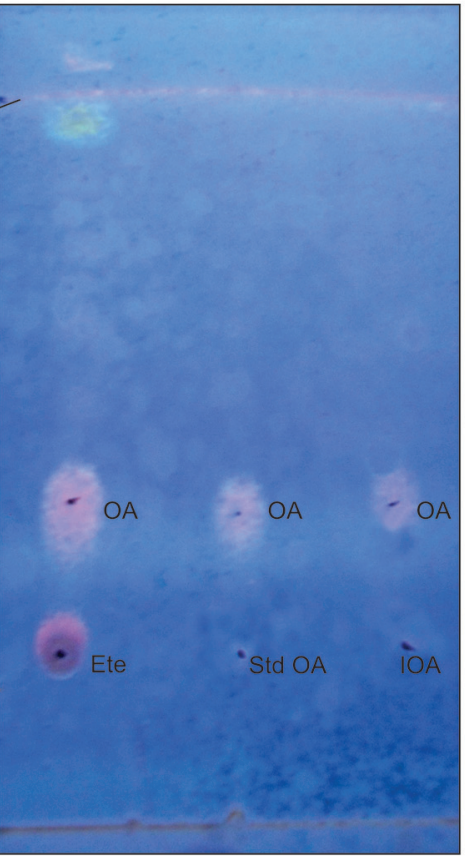

(B)

Fig. 3. TLC study. (A) Daylight visualization (B) UV 366 visualization.

Ete: Ethanolic extract of E. caryophyllus, Std OA: Standard oleanolic acid, IOA: Isolated oleanolic acid, OA: Oleanolic acid. 
$[\mathrm{M}+\mathrm{Na}]^{+}$(Ludwig et al., 2014) at $\mathrm{m} / z 479.349541$ and $[\mathrm{M}+\mathrm{H}]^{+}$at $m / z 457.366982$ (cald. For $\mathrm{C}_{30} \mathrm{H}_{48} \mathrm{O}_{3}, 456.3$ ) (Huang et al., 1999) correspond well with the literature (Wang et al., 2016).

${ }^{13} \mathrm{C}$ NMR spectrum showed 30 carbon atoms as given corresponding to $\mathrm{C}_{30} \mathrm{H}_{48} \mathrm{O}_{3}$ (Figure 4):

37.166 (C-1), 27.261 (C-2), 79.123 (C-3), 38.480 (C-4), 55.296 (C-5), 18.378 (C-6), 32.534 (C-7), 38.837 (C-8), 47.713 (C-9), 33.894 (C-10), 22.780 (C-11), 122.690 (C-12), 143.702 (C-13), 41.681 (C-14), 27.776 (C-15), 23.663 (C-16), 45.975 (C-17), 39.351 (C-18), 46.619 (C-19), 29.784 (C-20), 33.154 (C-21), 30.756 (C-22), 28.185 (C-23), 15.632 (C-24), 15.407 (C-25), 17.215 (C-26), 26.014 (C-27), 183.421 (C-28), 32.699 (C-29), 23.486 (C-30).
The signal at $\delta$-183.421 indicated the presence of carbonyl group assigned to $\mathrm{C}-28$. The seven peaks at $\delta-28.185,15.632,15.407,17.215,26.014,32.699$, and 23.486 are assigned to the seven methyl groups corresponding to C-23, C-24, C-25, C-26, C-27, C-29, and $\mathrm{C}-30$, respectively, while peaks at $\delta-122.690$ and $\delta-143.702$ represented the presence of a pair of $\mathrm{sp}^{2}$ hybridized olefinic carbon atoms assigned to $\mathrm{C}-12$ and C-13, respectively.

${ }^{1} \mathrm{H}$ NMR spectrum (Figure 5) exhibited the presence of methyl groups at $\delta 0.75(3 \mathrm{H}, \mathrm{H}-26), 0.76(3 \mathrm{H}, \mathrm{H}-24)$, 0.89 (3H, H-29), 0.91 (3H, H-25), 0.97 (3H, H-30), 0.98 $(3 \mathrm{H}, \mathrm{H}-23), 1.13$ (3H, H-27). The spectrum also showed the presence of oxygenated methine proton at $\delta 3.21(1 \mathrm{H}$, $\mathrm{H}-3)$, while the olefinic proton of $\mathrm{C} 12-\mathrm{C} 13$ showed it at $\delta$ $5.27(1 \mathrm{H}, \mathrm{H}-12)$, in accordance with those in the literature (Ngo et al., 2018).
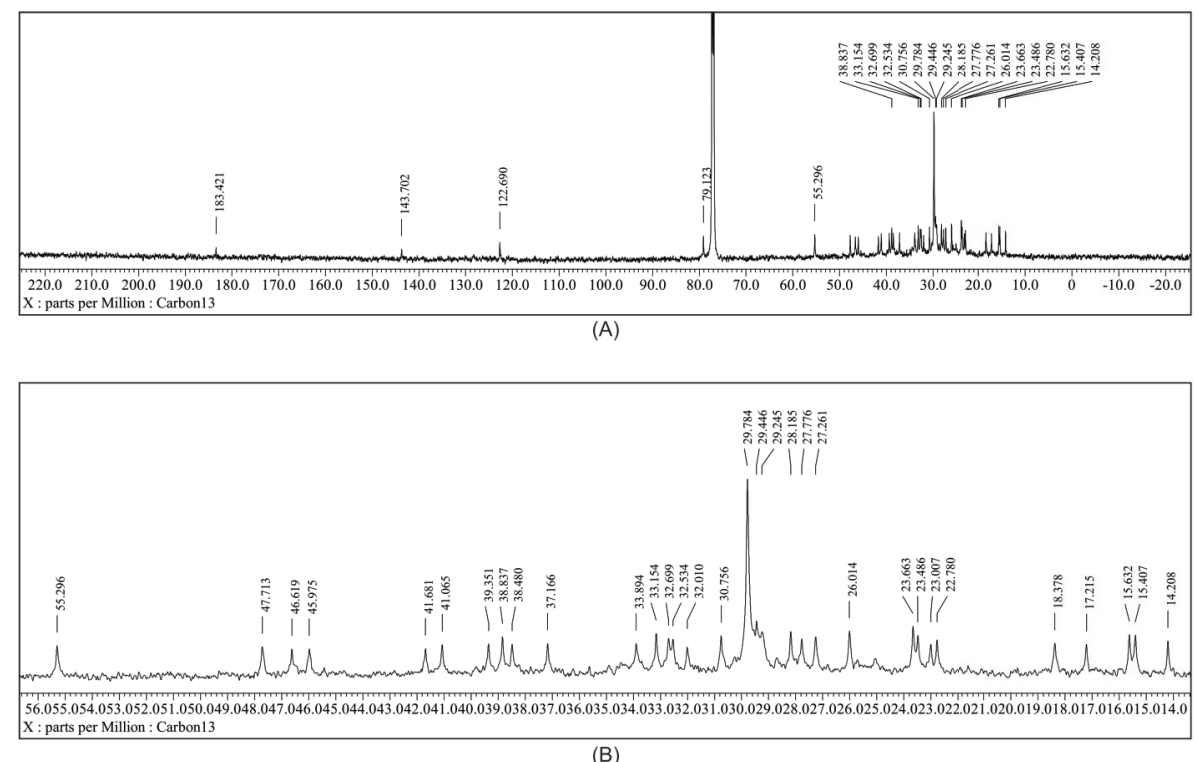

Fig. 4. ${ }^{13} \mathrm{C}$ NMR study. (A) Full spectrum. (B) Expanded region of an isolated oleanolic acid.

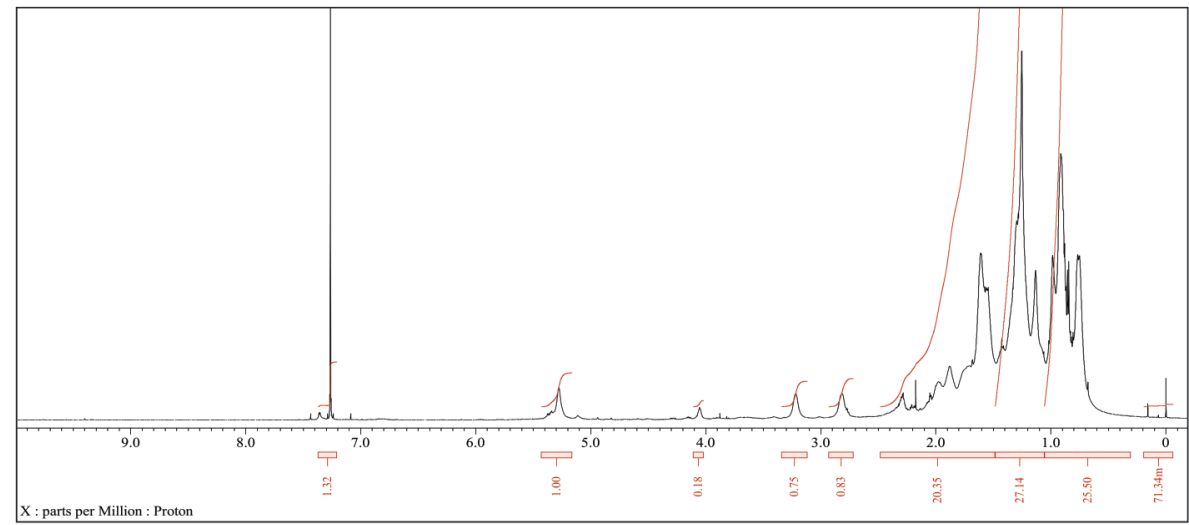

Fig. 5. ${ }^{1} \mathrm{H}$ NMR spectrum of an isolated oleanolic acid. 
In order to determine the purity of an isolated oleanolic acid by HPLC, the retention time was found to be 14 minutes (Figure 6).

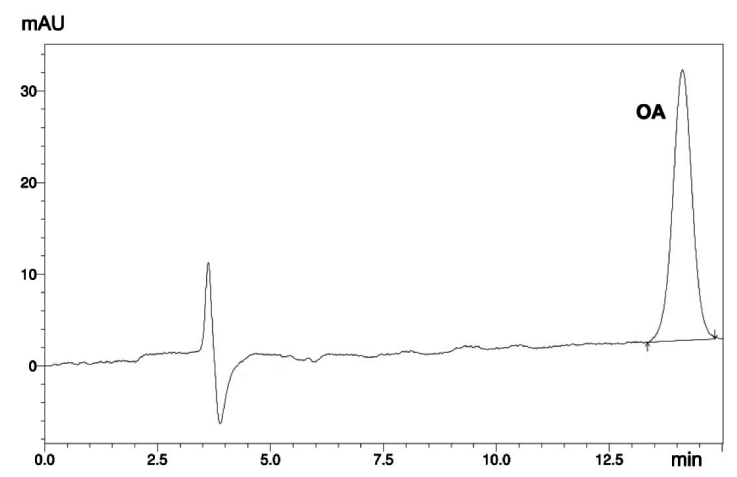

Fig. 6. Representative HPLC chromatogram of an isolated oleanolic acid in concentration of $40 \mu \mathrm{g} / \mathrm{mL} \mathrm{OA}$ : oleanolic acid.

According to the linear regressive relation between concentration and absorption peak area $(5 \mu \mathrm{g} / \mathrm{ml}-$ $115257.6 ; 10 \mu \mathrm{g} / \mathrm{ml}-228534.8 ; 20 \mu \mathrm{g} / \mathrm{ml}$ - 459030.4; $40 \mu \mathrm{g} / \mathrm{ml}-882060.8$ and $80 \mu \mathrm{g} / \mathrm{ml}-1634121.6)$, the calibration curve for oleanolic acid could be expressed using following equation:

$y=20206 x+37424\left(R^{2}=0.9982\right)$

where

$\mathrm{x}$ - concentration of oleanolic acid $(\mu \mathrm{g} / \mathrm{ml})$

$\mathrm{y}$ - corresponding absorption peak area of oleanolic acid.

By using the above equation, the concentration of an isolated oleanolic acid (taken as $60 \mu \mathrm{g} / \mathrm{ml}$ ) corresponding to peak area 1223108.6 was found to be $58.67 \mu \mathrm{g} / \mathrm{ml}$.

By putting the values for the determination of purity $(\mathrm{P}=(\mathrm{F} / \mathrm{T}) \times 100 \%)$, the purity of an isolated oleanolic acid was found to be $97.7 \%$.

Our novel method for the isolation of oleanolic acid from the flower buds of Eugenia caryophyllus involved the following easy steps:

- Removal of undesired foreign matter adhered to the cloves by washing with distilled water.

- Removal of unwanted polar constituents from the cloves using distilled water.

- Simple reflux extraction using ethanol as solvent.

- Decolorization of ethanolic extract by activated charcoal.

- Precipitation with distilled water and crystallization of oleanolic acid with methanol.
The method so developed meets the desired advantages as follows:

- It is economically viable, simple, cost-effective, less time consuming, and reproducible.

- There is no need to use the tedious chromatographic techniques (column chromatography) even the Soxhlet apparatus, and solvent recovery is possible.

- As cloves are easily and commercially available, it can have industrial utilization for the production of oleanolic acid. Further, the increased demand of cloves can boost up the national economy and development of cottage industries through its cultivation and production.

\section{Conclusion}

Concluding the aforementioned studies, an economically viable method for the isolation of the oleanolic acid from the flower buds of Eugenia caryophyllus (Spreng.) was successfully developed. The yield of oleanolic acid was found to be $1.8 \mathrm{~g} / 100 \mathrm{~g}$ dry matter $(1.8 \%)$. The isolated product, oleanolic acid, was characterized and confirmed by DSC, TLC, FTIR, ESI-HRMS, and NMR studies. Further, the purity of an isolated oleanolic acid was determined by HPLC, and it was found to be $97.7 \%$ pure.

\section{Conflict of interest}

The authors declare that there are no known conflicts of interest associated with this publication and the institutions where the work has been carried out.

\section{ACKNOWLEDGEMENTS}

The authors are grateful to the SAIF IIT Bombay for NMR, CIF Savitribai Phule University Pune for ESIHRMS, IISER Bhopal for DSC, SAIF Panjab University Chandigarh for FTIR studies, and CIF SRSIP Durg for other instrumental facilities.

\section{References}

Araújo, A.A.S., Bezerra, M.S., Storpirtis, S. \& Matos, J.R. (2010). Determination of the melting temperature, heat of fusion, and purity analysis of different samples of zidovudine (AZT) using DSC. Brazilian Journal of Pharmaceutical Sciences, 46(1):37-43.

Ayeleso, T.B., Matumba, M.G. \& Emmanuel, M. (2017). Oleanolic acid and its derivatives: Biological 
activities and therapeutic potential in chronic diseases. Molecules, 22 (11): 1915.

Duan, L., Yang, Z., Jiang, X., Zhang, J. \& Guo, X. (2019). Oleanolic acid inhibits cell proliferation migration and invasion and induces SW579 thyroid cancer cell line apoptosis by targeting forkhead transcription factor A. Anticancer Drugs, 30(8): 812-820.

Fai, Y.M. (2009). A review on presence of oleanolic acid in natural products. Natura Proda Medica, 2: 77-290.

Gohari, A.R., Saeidnia, S., Hadjiakhoondi, A., Abdoullahi, M. \& Nezafati, M. (2009). Isolation and quantificative analysis of oleanolic acid from Satureja mutica Fisch. \& C. A. Mey. Journal of Medicinal Plants, 8(5): 65-69.

Han, Z., Wang, M., Wang, L., Qu, H., Li, P., et al. (2013). Chemical analysis of burdock root constituents. Asian Journal of Chemistry, 25(5): 2573-2576.

Heinzen, R.A., Scidmore, M.A., Rockey, D.D. \& Hackst adt T. (1996). Differential interaction with endocytic and exocytic pathways distinguish parasitophorous vacuoles of Coxiella burnetii and Chlamydia trachomatis. Infection and Immunity, 64(3): 796-809.

Hossain, A.M. \& Ismail, Z. (2013). Isolation and characterization of triterpenes from the leaves of Orthosiphon stamineus. Arabian Journal of Chemistry, 6(3): 295-298.

Huang, N., Siegel, M.M., Kruppa, G.H. \& Laukien, F.H. (1999). Automation of a fourier transform ion cyclotron resonance mass spectrometer for acquisition, analysis, and e-mailing of high-resolution exact-mass electrospray ionization mass spectral data. Journal of American Society for Mass Spectrometry, 10(11): 11661173.

Isah, M.B., Ibrahim, M.A., Mohammed, A., Aliyu, A.B., Masola, B., et al. (2016). A systematic review of pentacyclic triterpenes and their derivatives as chemotherapeutic agents against tropical parasitic diseases. Parasitology, 143(10): 1219-1231.

Kamatou, G.P., Vermaak, I. \& Viljoen, A.M. (2012). Eugenol-from the remote Maluku Islands to the international market place: A review of a remarkable and versatile molecule. Molecules, 17(6): 6953-6981.

Kim, G.J., Jo, H.J., Lee, K.J., Choi, J.W. \& An, J.H. (2018). Oleanolic acid induces p53-dependent apoptosis via the ERK/JNK/AKT pathway in cancer cell lines in prostatic cancer xenografts in mice. Oncotarget, 9(41): 26370-26386.

Li, R., Wu, Z.L., Wang, Y.J. \& Li, L.L. (2013). Separation of total saponins from the pericarp of Sapindus mukorossi Gaerten. by foam fractionation. Industrial Crops and Products, 51: 163-170.

Liu, C.M., Huang, J.Y., Sheng, L.X., Wen, X.A. \& Cheng, K.G. (2019). Synthesis and antitumor activity of fluorouracil - oleanolic acid/ursolic acid/glycyrrhetinic acid conjugates. Medicinal chemistry communications, 10(8): 1370-1378.

Liu, J. (1995). Pharmacology of oleanolic acid and ursolic acid. Journal of Ethnopharmacology, 49: 57-68.

Lu, Y-F., Wan, X-L., Liu, J. \& Xu, Y. (2013). Repeated oral administration of oleanolic acid produces cholestatic liver injury in mice. Molecules, 18(3): 3060-3071.

Ludwig, B., Geib, D., Haas, C., Steingroewer, J., Bley, T., et al. (2014). Whole-cell biotransformation of oleanolic acid by free and immobilized cells of Nocardia iowensis: Characterization of new metabolites. Engineering in Life Sciences, 15:108-115.

Meshram, G.A. \& Khamkar, S.S. (2014). Effect of oleanolic acid isolated from garlic leaves on carbohydrate metabolizing enzymes, In Vitro. International Journal of Pharma Sciences and Research, 5(12): 988-991.

Mishra, T., Arya, R.K., Meena, S., Joshi, P., Pal, M., et al. (2016). Isolation, characterization and anticancer potential of cytotoxic triterpenes from Betula utilis Bark. PLOS ONE, 11(7): e0159430.

Ngo, Q.M.T., Cao, T.Q., Woo, M.H., Min, B.S. \& Weon, K.Y. (2018). Cytotoxic triterpenoids from the fruits of Ligustrum japonicum. Natural Product Sciences, 24(2): 93-98.

Nowak, R., Wójciak-Kosior, M., Sowa, I., SokołowskaKrzaczek, A., Pietrzak, W., et al. (2013). Hptlcdensitometry determination of triterpenic acids in Origanum vulgare, Rosmarinus officinalis and Syzygium aromaticum. Acta Poloniae Pharmaceutica, 70(3): 413418.

Paszel-Jaworska, A., Romaniuk, A. \& Rybczyńska, M. (2014). Molecular mechanisms of biological activity of oleanolic acid - A source of inspiration for a new drugs design. Mini-Reviews in Organic Chemistry, 11(3): 330342.

Rangari, V.D. (2012). Pharmacognosy \& Phytochemistry. 
Career Publications, Nashik. Pp. 357-360.

Reyes-Zurita, F.J., Medina-O'Donnell, M., FerrerMartin, R.M., Rufino-Palomares, E.E., MartinFonseca, S., et al. (2016). The Oleanolic acid derivative, 3-O-succinyl-28-O-benzyl oleanolate, induces apoptosis in B16-F10 melanoma cells via the mitochondrial apoptotic pathway. RSC Advances, 6: 93590-93601.

Shanmugam, M.K., Dai, X., Kumar, A.P., Tan, B.K., Sethi, G., et al. (2014). Oleanolic acid and its synthetic derivatives for the prevention and therapy of cancer: Preclinical and clinical evidence. Cancer Letters, 346(2): 206-216.

Sultana, N. \& Ata, A. (2008). Oleanolic acid and related derivatives as medicinally important compounds. Journal of Enzyme Inhibition and Medicinal Chemistry, 23(6): 739-756.

Verma, S.C., Jain, C.L., Nigam, S. \& Padhi, M.M. (2013). Rapid extraction, isolation, and quantification of oleanolic acid from Lantana camara L. roots using microwave and HPLC-PDA techniques. Acta Chromatographica, 25(1): 181-199.

Walter, E.D. (1961). Isolation of oleanolic acid and saponin from trefoil (Lotus corniculatus, var. viking). Journal of Pharmaceutical Sciences, 50(2): 173.

Wang, C.M., Chen, H.T., Wu, Z.Y., Jhan, Y.L., Shyu, C.L., et al. (2016). Antibacterial and synergistic activity of pentacyclic triterpenoids isolated from Alstonia scholaris. Molecules, 21(2): 139.

Widmann, G. \& Scherrer, O. (1991). A new program for DSC purity analysis. Journal of Thermal Analysis and Calorimetry, 37(8): 1957-1964.

Xu, K., Chu, F., Li, G., Xu, X., Wang, P., et al. (2014). Oleanolic acid synthetic oligoglycosides: a review on recent progress in biological activities. Pharmazie, 69(7): 483-495.

Submitted : 14/11/2019

Revised : 03/03/2020

Accepted : 17/03/2020

DOI : 10.48129/kjs.v48i1.8620 